\title{
Technical Competencies - A Versatile Framework for Learning Practical Knowledge
}

\author{
Randall Tagg
}

Department of Physics, University of Colorado Denver, CB 157, Denver, CO 80217-3364

\begin{abstract}
Students need a wide array of practical skills and knowledge in order to pursue advanced laboratory work, research, innovation, and technical jobs in industry. This knowledge begins with tool and shop use and extends to a capacity for basic electronics design, construction, and testing. Beyond these common skills, students need to come up to speed quickly on specialized techniques specific to a particular problem: examples include vacuum technique, plumbing, use and calibration of sensors, motor control, pneumatic actuators, etc. We provide a physical inventory, a web site, and a learning model that provides access to an expanding array of practical knowledge topics. The goal of this ongoing project is to develop a versatile framework for students to obtain and certify a personal repertoire of technical competencies.
\end{abstract}

Keywords: practical knowledge, technical competencies, applications of physics, independent projects, innovation. PACS: $01.40 . \mathrm{Gb}, 01.50 . \mathrm{Pa}, 01.50 . \mathrm{Qb}, 01.85 .+\mathrm{f}$

\section{INTRODUCTION}

Current technologies and events create a time of extraordinary opportunity and extraordinary need for physics students who are practical-minded. The creative, hands-on, problem-solving ethos that enables a physics student to effectively contribute in a research lab can equally serve a wider community. This includes employers who need people with the broad fundamental understanding provided by physicists, small businesses formed or assisted by entrepreneurialminded students, communities that face important and sometimes overwhelming - challenges, and K-12 schools who need college-age mentors to inspire young students to pursue technical careers.

While physics training endows students with the ability to think rigorously and creatively, the opportunities described above require that students translate and adapt their knowledge through a battery of practical skills. An important addition is the tacit knowledge that comes through experience in using these skills on authentic problems, guided when possible by experienced practitioners.

This paper presents an environment and a flexible learning model designed to provide such augmented training to physics students. Three central ideas are described: (1) the partitioning of practical knowledge common to many design and technical problems into fifty-two distinct categories, (2) the identification within each category of a set of technical competencies that are the "quanta" of practical learning, and (3) a physical infrastructure that supports such learning and provides a rich base of resources to work effectively on authentic challenges and innovative ideas. Each student assembles a selection of competencies into a personal repertoire. Such a repertoire, systematically achieved, documented, and experience-tested, can equip students with a major tool to serve the community and to advance themselves in pursuit of physics-based careers.

\section{TECHNOLOGIES}

A remarkable array of "cool" and relatively lowcost technologies exists to entice students to design and build - this is the allure of "maker spaces" that have become popular nationwide. Arduino micro-controllers provide an easy onramp to embedded computing with automated sensing and control. 3-D printers are appearing on lab benches and in workshops, transforming ideas quickly from concept to CAD drawing to physical realization. Cell-phone cameras of astonishing resolution can be converted into microscopes. A wise physics student takes advantage of these and other popular avenues for "hacking" and exploring. Such a student also can take a lesson from artists, who have playfully embraced "physical computing" to create animated displays and music ${ }^{1}$.

However, there is so much more to technology, both traditional and advanced. A perspective can either be derived from experience gained over decades of experimental physics research or else from observations quickly assimilated by taking apart and reverse-engineering surplus equipment and consumer goods. Consider what a Mars rover, a photocopier, and a toaster might have in common. These must be constructed from a selection of materials, they must have power sources, they all use heaters, and they require electronics and controls of varying degrees of sophistication. Of course, the Mars Rover and 
TABLE 1. Technology Areas

\begin{tabular}{|c|c|c|}
\hline Foundations & 19. Fluid systems & 37. Digital signal processing \\
\hline 1. Safety \& hazardous materials & 20. Thermal systems & 38. Advanced detection \& \\
\hline 2. Early prototyping & 21. Vacuum \& high pressure & measurement \\
\hline 3. Common tools & Electronics & 39. High-throughput data handling \\
\hline General technical issues & 22. Electronic components \& & Optics, fields \& particles \\
\hline 4. Materials & measurement & 40. Optical systems \\
\hline 5. Traditional manufacturing & 23. Analog signals & 41. Optoelectronics \& lasers \\
\hline 6. Advanced manufacturing & 24. Active devices & 42. Imaging \\
\hline 7. Structural systems & 25. Digital electronics & 43. Magnetic fields \&superconductors \\
\hline 8. Rigging \& materials handling & 26. Microcontrollers & 44. Electrical fields \& plasmas \\
\hline 9. Buildings \& infrastructure & 27. Human interfaces & 45. Particle beams \& detectors \\
\hline 10. Energy systems & 28. Radio-frequency electronics & 46. Health physics \& \\
\hline 11. Measurement \& standards & 29. Remote control \& telemetry & nuclear instrumentation \\
\hline 12. Sensors & 30. Microwave systems & Micro- and nanotechnology \\
\hline Mechanics & Computers, control \& advanced & 47. Microscopy \& micromanipulation \\
\hline 13. Mechanisms & instrumentation & 48. Microfabrication \& thin films \\
\hline 14. Actuators & 31. Computers & 49. Microdevices \& lab-on-a-chip \\
\hline 15. Vehicles & 32. Data storage & 50. Nanoscale microscopy \& \\
\hline 16. Rotating systems & 33. Networks \& data communication & measurement \\
\hline 17. Vibration \& chaos & 34. Control systems & 52. Nanoparticles \& self assembly \\
\hline 18. Sound \& ultrasound & 35. Automation & 52. Nanodevices \\
\hline & 36. Robotics & \\
\hline
\end{tabular}

photocopier also include some highly specialized components and systems. But even in the case of a consumer object like a toaster whose cost may only be $\$ 10$, we tend to take for granted the astonishing accumulation of technology that makes such a product feasible ${ }^{2}$.

By methodically thinking about the technologies involved in scientific and consumer devices, a list can be generated. One such list is shown in Table 1. There is no rigid delineation of topics: different people would compile different lists. The key point is that one is led to consider a wide variety of technologies as "applied physics". Some are basic, like safety and common tools. Others are currently under active development, such as robotics. Some have seen a recent resurgence, such as radio frequency electronics. Some require a higher level of sophistication, such as digital signal processing and advanced detection and measurement. An attempt is made to anticipate likely directions of expansion, such as nanotechnology.

The table also shows how these topics can be grouped into broad themes, such as mechanics and electronics. Several themes match up with disciplines of engineering. The challenge faced by physics students is to acquire enough practical knowledge without having to commit to a lengthy train of engineering prerequisites and to learn this material just in time to effectively use in projects. The challenge for physics programs is to determine how to make such learning available. These issues lead to a learning model that we think provides a versatile, studentcentered approach to gaining practical knowledge.

\section{LEARNING MODEL}

So we now pose the question: is there a systematic, scalable method by which students can access both common aspects of practical knowledge such as basic electronic measurement but also - when the need arises - learn more specialized techniques? These might include, for example, the construction of fluid handling systems or the design and tuning of proportionalintegral-differential (PID) controllers. Physics programs do offer courses in electronics and perhaps even in machine shop use, but the list in Table 1 clearly exhausts the capacity to organize formal courses. Moreover, different students may need to emphasize unique selections of topics, perhaps trading a wide range of electronics instruction for more skills in working with optics or mechanical systems.

Our approach is to identify, within each technology, a set of "technical competencies". While usage of this term varies, we choose a narrow construct: a technical competency is a focused set of skills and supporting concepts that enables a particular type of practical problem to be solved. Moreover, we limit the scope of a technical competency to knowledge that might be gained - at a first level of understanding - in perhaps two to ten hours of concentrated effort. Some basic technical competencies are the correct use of digital multimeters to measure current, potential, and resistance and the procedure for using two mirrors to align the position and angle of a laser.

While the previous examples are technical competencies that are procedural and instrumental, many competencies will be oriented towards design. 
TABLE 2. Technical competency attributes

\begin{tabular}{|c|c|}
\hline Capacity & Proficiency Criterion \\
\hline Design awareness & $\begin{array}{l}\text { When confronted with a design } \\
\text { challenge, student can quickly list } \\
\text { three or more choices of technical } \\
\text { components that might provide the } \\
\text { necessary capability. }\end{array}$ \\
\hline Design rationale & $\begin{array}{l}\text { Student can cite two or more } \\
\text { scientific principles underlying the } \\
\text { behavior of a technical component, } \\
\text { with an appreciation for how these } \\
\text { historically drove the development } \\
\text { of the associated technology. }\end{array}$ \\
\hline $\begin{array}{l}\text { Design } \\
\text { constraints }\end{array}$ & $\begin{array}{l}\text { Student can precisely enumerate two } \\
\text { or more constraints that must be } \\
\text { satisfied in employing a component } \\
\text { in a design. }\end{array}$ \\
\hline $\begin{array}{l}\text { Quantitative } \\
\text { performance } \\
\text { metrics }\end{array}$ & $\begin{array}{l}\text { Student knows two or more } \\
\text { performance metrics determining } \\
\text { the suitability of a technical } \\
\text { component, with a rough idea of the } \\
\text { numerical values that ought to be } \\
\text { achieved. }\end{array}$ \\
\hline $\begin{array}{l}\text { Performance } \\
\text { modeling }\end{array}$ & $\begin{array}{l}\text { Student can use one or more } \\
\text { mathematical relationships } \\
\text { governing a technical component's } \\
\text { behavior to predict a measurable } \\
\text { aspect of performance. }\end{array}$ \\
\hline $\begin{array}{l}\text { Design } \\
\text { implementation }\end{array}$ & $\begin{array}{l}\text { Student can incorporate a } \\
\text { component into a design and } \\
\text { demonstrate that the chosen } \\
\text { component reliably meets the needs } \\
\text { of the design under a range of } \\
\text { operating conditions. }\end{array}$ \\
\hline $\begin{array}{l}\text { System } \\
\text { integration }\end{array}$ & $\begin{array}{l}\text { Student can model the interaction of } \\
\text { the component with one or more } \\
\text { other elements of a complex } \\
\text { technical system, suggesting } \\
\text { strengths and weaknesses of the } \\
\text { component from a system behavior } \\
\text { standpoint. }\end{array}$ \\
\hline $\begin{array}{l}\text { Skills for install- } \\
\text { ation and } \\
\text { operation }\end{array}$ & $\begin{array}{l}\text { Student is readily able to install a } \\
\text { component into a designed system } \\
\text { and/or to operate the component } \\
\text { once installed, and is able to refine } \\
\text { the installation or operation as work } \\
\text { proceeds. }\end{array}$ \\
\hline Test protocols & $\begin{array}{l}\text { Student can set up a test protocol } \\
\text { that is motivated by the design } \\
\text { context and can enumerate } \\
\text { acceptance criteria. }\end{array}$ \\
\hline $\begin{array}{l}\text { Design } \\
\text { improvement }\end{array}$ & $\begin{array}{l}\text { Student can identify means to } \\
\text { quantitatively improve on one or } \\
\text { more performance metrics. }\end{array}$ \\
\hline
\end{tabular}

For example, how does one design op amp circuits for signal conditioning? How can one use transistors and diodes to make a push-pull power amplifier? What kind of light source can best be adapted and controlled for a biophysics experiment?
With this design orientation in mind, we define a set of attributes that might be considered the end result of acquiring a technical competency. These are listed in Table 2 along with a description of the level of proficiency achievable by an advanced physics student.

The goal is to give students a succinct exposure to the knowledge needed for such competencies. A key additional aspect, requiring further time - perhaps even extending over the duration of an extended project - is to "field test" the knowledge in an application. When possible, this should arise naturally out of a student's ongoing work in projects that the student has defined. An alternative is to create scenarios for applying a set of technical competencies: we call these application context examples (ACE's), and say that students should aim to "ACE" their new knowledge.

\section{Example}

Consider a technical competency in the selection and use of light sources. This is included in the "Optical Systems" technology area. The following is a design narrative for an actual senior thesis project requiring a light source for a biophysics experiment in plant growth. Such a narrative, either written or oral, could be prepared by a student in order to be certified in the competency.

Design awareness: The student thinks of three choices: incandescent, fluorescent, or LED. Design rationale: the student selects LED's as the desired source and has worked to understand the physical basis and spectral composition of the light production and the corresponding device characteristics in terms of current-voltage relationships. Design constraints: the light source will be in a growth chamber so heat production and fire hazard are of concern; the system must also operate unattended for several days.

Quantitative performance metrics: literature shows that illumination must fall within certain spectral bands and that the peak illumination level must be a certain value in micromoles of photons per square meter per second. Performance modeling: having chosen a combination of red and blue LED's as the desired source, the student creates a model of the spatial profile of illumination using the LED's documented angular distribution. Spectral and luminous intensity data is converted to radiometric quantities and is used to determine how many LED's will be needed to reach the target illumination.

Design implementation: the student works out how to construct an array of LED's with current-limiting resistors and has decided to use a surplus computer power supply operated from a retail-store 24-hour power-switch timer. A mechanical arrangement using all-thread is designed to support the LED array from the top of the growth chamber in a way that allows for 
position adjustment. System integration: the impact of the LED array on the chamber's temperature control and on time-lapse video monitoring of plant growth are considerations given to system performance.

Skills for installation and operation: the student uses other competencies to carry out the installation. These include the use of hand tools and power tools as well as circuit building and soldering. New knowledge is gained while modifying the arrangement and structural support of the LED's to provide the most efficient illumination. Test protocols: the student borrows a calibrated photocell to measure illumination levels and checks operating temperature over a day of use. Design improvement: a next step is to control the LED power using a micro-controller with D/A output to continuously modulate the light intensity in a way that better mimics natural conditions.

\section{INFRASTRUCTURE}

An environment is needed to deliver such learning, both of the specific competencies and through ongoing and highly varied application projects. We have created a large versatile lab that houses resources across the entire range of topics. There are three types of physical resources and one virtual resource.

The first physical resource is an assemblage of kits that students can check out (or which can be brought to a classroom): these contain the materials needed to pursue an individual technical competency. As much as possible, we have aimed to put these kits inside robust 17-liter plastic boxes with clamp-on lids. A further design goal has been to try, as much as possible, to use components readily available through retail suppliers in order to contain costs and make this model transferrable to varied communities and to K-12 schools. Of course, certainly specialized items will have to be included since it is a clear goal to expose students to professional-grade components.

The second physical resource is a large stock of supplies that can be used to adapt technical knowledge to individual projects. The lab has been organized into supply bays each comprised of three related technologies. Stocking the lab requires adroit use of donations, surplus suppliers and special sales. The intent is to grow the lab opportunistically.

The third physical resource - still under development - is to gradually equip individual sections with major pieces of equipment. Examples include optical microscopes, a vacuum deposition chamber, and a high-temperature oven ... as well as items that are components expected of contemporary maker spaces such as a 3-D printer, a laser etcher, and some level of CNC machining. While much of the learning is intended to be "on demand" and self-paced, the use of such specialized equipment requires times of instruction when individual expert guidance and careful qualification are required.

The virtual support of this learning and project work is a web site. It contains landing pages for each of the fifty-two technologies and organizes content for the technical competencies as well as other information such as supply inventories and bibliographies ${ }^{3}$. Still under development, the site URL is:

https://sites.google.com/site/inventorsyeara/

\section{ONGOING CHALLENGES}

Creating an institutional framework for this rationalized, flexible, student-centered approach has been difficult. One issue is space: we recently set up a university-level lab in a 2500 square-foot auto shop next to a high school. We are now relocating to better integrate college student projects, hoping to double the space with more open common areas for student work. The resulting size is comparable to a basketball gym. Our aim is to create a strong case that the learning and project outcomes, applicable to students well beyond physics majors, justify such a commitment. A narrower selection of topics and a focus only on kits reduces space requirements but this works against achieving a critical complexity within which individualized learning and original projects can flourish.

The other major obstacle is the creation of suitable formats for on-demand learning. Academic scheduling usually requires full-semester courses and minimum enrollments. We put simplified versions of several competencies into a year-long course for high school students. However, the goal is to make such learning individual and on-demand at $\mathrm{K}-12$, college, and graduate levels. Society greatly needs physics students whose vision and creativity can harness such training.

\section{ACKNOWLEDGMENTS}

This work included collaboration with Aurora Public Schools, with thanks to Carol McBride, Michael Bautista, Lynn Fair, Ron Vasquez, Judy Bleakley, John Miller, Alice Sampson, Brandon Whittaker and many high-school teams and undergraduate mentors.

\section{REFERENCES}

1. D. O'Sullivan and T. Igoe, Physical Computing: Sensing and Controlling the Physical World With Computers (Thomson Course Technology PTR, 2004).

2. T. Thwaites, The Toaster Project: Or a Heroic Attempt to Build a Simple Electric Appliance From Scratch (Princeton Architectural Press, 2011).

3. A good general reference is J. H. Moore, C. C. Davis, M. A.Coplan, and S. C. Greer, Building Scientific Apparatus, 4th ed. (Cambridge University Press, 2009). 